\title{
Dependence of Digital Economy on Free Labor
}

\author{
Analiza D. Resurreccion
}

\begin{abstract}
This paper focuses on the development of digital economy as well as its dependence on free labor. The researcher reviews related literature and studies, and conducts interview among young entrepreneurs to seek answers to questions related to the aforementioned. Digital economy is not just a phenomenon; it is a formation which intersects on the one hand with the postmodern cultural economy and on the other hand with the information industry that constitutes a challenge to a theoretical and practical engagement with the question of labor. Digitization affects the metabolism of the economy the same way it significantly affects the capacity of humans to communicate across time and space. It is an important area of experimentation which relies on free labor.
\end{abstract}

Index Terms-Dependence, digital economy, digitization, free labor.

\section{INTRODUCTION}

Working in the digital media industry was never as much fun as it was made out to be [1]. Certainly, for the workers of the best known and most highly valued companies, work might have been a brief experience of something that did not feel like work at all. On the other hand, even during the dot-com boom the 'netslaves' of the homonymous webzine had always been vociferous about the shamelessly exploitative nature of the job, its punishing work rhythms and its ruthless casualization. They talked about '24/7 electronic sweatshops' complained about the 90-hour week and the 'moronic management of new media companies'. Antagonism in the new media industry also affected the legions of volunteers running well-known sites for the Internet giants [1].

These events pointed to an inevitable backlash against the glamorization of digital labor, which highlighted its continuities with the modern sweatshop and the increasing degradation of knowledge work. Yet the question of labour in a 'digital economy' as an innovative development of the familiar logic of capitalist exploitation is not so easy dismissed. The netslaves are not simply a typical form of labor on the Internet; they also embody a complex relation to labor, which is widespread in late capitalist societies [1].

In Richard Barbrook's definition, the digital economy is characterized by the emergence of new technologies (computer networks) and new types of worker (such as digital artisans). It is a mixed economy: it includes a public element (the state's funding of the original research that produced ARPANET, the financial support to academic activities which had a substantial role in shaping the culture of the Internet); a market-driven element (a latecomer that

Manuscript received January 14, 2014; revised March 6, 2014.

Analiza D. Resurreccion is with the De La Salle Lipa, Philippines (email: haildaphnenow@gmail.com). tries to appropriate the digital economy by reintroducing commodification); and a gift economy (the true expression of the cutting edge of capitalist production which prepares its eventual overcoming into a future 'anarcho-communism') [1], [2].

Tiziana Terranova writes, "Simultaneously voluntarily given and unwaged, enjoyed and exploited, free labor on the Net includes the activity of building Web sites, modifying software packages, reading and participating in mailing lists, and building virtual spaces on MUDs and MOOs. Far from being "unreal," empty space, the Internet is animated by cultural and technical labor through and through, a continuous production of value [3].

In this light, the researcher studies the emergence of digital economy. The researcher also seeks to find out its effect to the economy's metabolism and its dependence on free labor.

\section{THEORETICAL FRAMEWORK}

Karl Marx's Critical Theory of Labor serves as the researcher's guide in dealing with the dependence of digital economy on free labor. Marx's concept of "value" is not identical with "wealth" as in classical economics, but refers to the mutual mediation of the products of labor by which they are constituted as commodities [4].

This mediation can be understood as the embodiment of "abstract labor" in the commodities. The concrete labor which goes into making the products is not itself the effective measure of value under capitalism, but only the average time actually required at the given stage in economic evolution to produce them. It is this average which Marx calls abstract labor [4].

The effectiveness of this distinction between concrete and abstract labor is of course guaranteed by the market, where differences in the concrete labor embodied in goods are averaged out in the practice of buying and selling commodities. On the 2 market, then, what might otherwise appear as a merely conceptual entity, a certain theoretical average, becomes socially active. This is what Marx calls a "real abstraction, "an abstraction that has achieved institutional reality [4].

Marx's theory is based on this double character of labor as a concrete use value productive of "real wealth," and as an abstract measure of value. While he does argue that labor in this double form is determining for capitalist social life, Marx does not project this hypothesis back onto earlier stages of economic history, nor does he privilege labor in relation to other institutions in the history of the species. Its privilege under capitalism is specifically tied to the commodity form and has no trans-historical significance. Marx's theory thus belongs to capitalism as its immanent critique [4]. 
Because value measures wealth under capitalism, and governs the behavior of capitalists and workers thereby, capitalism possesses a specific historical dynamic. This dynamic is expressed concretely in the gradual transformation of production from handicraft to industry in the course of which labor is deskilled and subsumed under capital. This process leads to the creation of a specifically capitalist technology and labor process. Working class struggle plays an unwitting functional role in furthering that evolution, to which it is a response [4].

At the most general level, this historical dynamic has a peculiar temporality based on the ever rising threshold of value as technical progress continually reduces the average time required to produce the same amount of goods. Although the quantity of material goods increases and technology advances, capitalism always finds itself at the same place in terms of value, ever striving toward higher and higher levels of achievement in the race to produce for production's sake [4].

This dynamic contains the internal contradiction of capitalism. Postone is persuasive when he insists on the basis of his analysis that that contradiction is not between capitalist relations of distribution and industrial production, nor between capitalists and workers. Rather, capitalist temporality drives technical progress toward a stage in which human labor, the measure of value, is less and less important to production. The system continues to be governed by a factor, labor, which was once its heart and soul, but which is increasingly marginal. That is the real contradiction Marx identifies in capitalism [4].

As wealth accumulates independently of human labor, the absurdity of capitalism becomes more and more apparent. It no longer makes sense for human beings to be mere puppets of the structure of their own laboring practices. The potential is there for a completely different way of producing and living. The powerful industrial system could be applied "reflexively" to its own reconstruction in a more humane and ecologically sound form that would measure wealth not in terms of value but in terms of human needs democratically articulated in the public sphere [4].

Marx's writes of non-alienated labor, focused on the individual - individual expression, pleasure, and personality. This is the kind of labor that Chris Anderson in his book Free: The Future of Radical Price (2009) says people do free, to fulfill something for themselves that their job fails to satisfy. It may not be in the sector that Marx envisioned, but the internet has nonetheless created an avenue for nonalienated labor for all. The internet provides the opportunity for sharing easily for the benefit of others with recognition and satisfaction in return. The internet allows for these connections, and for immediacy [5].

Paddy Scannel in his book Media and Communication writes that "alienated labour shows up first in the fact that the labourer, even before he starts to work has already sold himself for a wage". When one works not for a wage, as in the genuinely Free economy, this alienation does not have the same opportunity to begin. It could be argued that one instead sells oneself for attention or reputation, but these are more benign [6]. In her "Chris Anderson's Free adds much to The Long Tail, but falls short," Cory Doctorow shows that free labor goes even beyond that [7]. Where commodified labor is "the denial of social existence [6], the internet reinforces social connection in many ways, particularly with interactions involving free labor. Everyone involved can benefit and contribute, of their own will, donating time, attention and effort for the reasons they deem worthy.

Marx says that hidden in the commodity is the arte of exploitation, i.e. the difference between what the capitalist makes and what the worker makes. If money is removed from the equation, or if the worker provides what he makes directly, it seems that this effect could be erased.The labor conditions outlined by Marx still exist, but the free labor economy described by Anderson and Doctorow [5], [7] provides a way for people to labor for themselves and for a common good, with control over the process and their involvement, and the possibility of satisfaction and self expression.

At some point, the speed of the digital economy, its accelerated rhythms of obsolescence, and its reliance on (mostly) "immaterial" products seemed to fit in with the postmodern intuition about the changed status of the commodities whose essence was said to be meaning (or lack of) rather than labor (as if the two could be separable). The work of Jean-François Lyotard in The Postmodern Condition is mainly concerned with knowledge, rather than intellectual labor, but still provides a useful conceptualization of the reorganization of labor within the productive structures of late capitalism [8]. The recurrent complaint that the Internet contributes to the disappearance of reality is then based both in humanistic concerns about "real life" and in the postmodern nihilism of the recombinant commodity [9]. Hyperreality confirms the humanist nightmare of a society without humanity, the culmination of a progressive taking over of the realm of representation. Commodities on the Net are not material and are excessive (there is too much of it, too many Web sites, too much clutter and noise) with relation to the limits of "real" social needs.

It is possible, however, that the disappearance of the commodity is not a material disappearance but its visible subordination to the quality of labor behind it. In this sense the commodity does not disappear as such; rather, it becomes increasingly ephemeral, its duration becomes compressed, and it becomes more of a process than a finished product. The role of continuous, creative, innovative labor as the ground of market value is crucial to the digital economy. The process of valorization (the production of monetary value) happens by foregrounding the quality of the labor that literally animates the commodity.

\section{STATEMENT OF THE PROBLEM}

This qualitative research is a study of the dependence of digital economy on free labor.

Specifically, it seeks to answer the following questions:

- How has the concept of digital economy emerged?

- In what ways have digital economy affected the labor process?

- What defines free labor in the context of digital economy? 
- How has free labor contributed to the development of digital economy?

\section{RESULTS AND DisCUSSION}

This chapter presents the discussion of the data gathered from the research.

1) Digital economy emerged in the late 1990s. As a term, it seems to describe a formation which intersects on the one hand with the postmodern cultural economy (the media, the university and the arts) and on the other hand with the information industry (the information and communication complex) [1]. Such an intersection of two different fields of production constitutes a challenge to a theoretical and practical engagement with the question of labor, a question which has become marginal for media studies as compared with questions of ownership (within political economy) and consumption (within cultural studies).

Barbrook refers to this digital economy as the 'gift economy,' a space autonomous from the market where people communicate over long distances without spending money, trade information freely, and form communities around ideas of mutual interest [2], [10].

2) By comparing something as simple as the post office and its delivery of physical mail to the digital electronic mail systems of today (even though they are relatively primitive), you can begin to understand the effect of digitization on the metabolism of the economy [11]. The benefits of e-mail are not just that messages move faster (approaching the speed of light compared to mail trucks). Nor that there is additional convenience in being able to send messages with the flick of a keyboard to a distribution list. Nor that there is a permanent searchable record of communications. Nor that "shadow functions," like walking to the mail box or playing telephone tag, are reduced. Although all those benefits are real enough, the point is that e-mail is just the beginning of a whole new way of human collaboration. Product planners are working as a team from various locations. People can work just as effectively from home or their hotel room as they can in the office. Similar change is coming to every aspect of commerce, management, and learning throughout the economy. As text-based e-mail systems are replaced by multimedia mail in which your message contains information in many forms, including video the capacity of humans to communicate across time and space will be affected significantly [11].

Young entrepreneurs from Batangas City, Lipa City, and Mabini in Batangas also prove the numerous effects of digital economy to labor process.

Mr. Jesus Rommelson Cantos, President of Likha Internet that has been operating for five years said that online applications like Google Drive, Facebook, and others, as well as Customer Relations Software enabled his team to

- Delegate financial aspects of the business (proposal, invoicing, payment records), thus letting them focus on their own work

- Promote their services and make it an integral part of their marketing efforts
- Share documents, contacts, event details and files easily and for free, and

- Track their progress/project timeline/calendar on the fly. They even use their mobile phones to do so.

Mr. Juan Teodoro Katigbak, Management Staff at Batangas Agribusiness Center which has been operating for almost 20 years claims that the advent of innovative technology has made it possible to streamline certain operations that used to be done manually, like the implementation of a centralized accounting system that uses a software for ease of use and accessibility.

Other forms of influence can be seen in smaller scales like the use of digital time-in systems, the use of email as an alternative (and primary) means of communication with clients, and of course, the utilization of the web in important research and industry developments.

Mr. Zeus Dimaculangan, Manager and Global Dealer/Franchisee at Lucky ZAM Pawnshop and Global Pinoy Remittance and Services/UPS which has been operating for 26 years and 4 years respectively states that they

- Extend marketing tools and promotion through Social Networking sites

- Automate their tasks in workplace (Remote Management via Team Viewer)

- Extend communication in Franchiser-Franchisee likewise CSR via email and yahoo messenger/ Skype

- Ease transaction via smart phones (Loading, Ticketing, Remittances)

- Automate payroll updates likewise bank deposits to dealers/suppliers via electronic banking systems online

Mr. Ace Aimon Villanueva, the owner of Ace D One General Merchandise mentions that on its entire three years of operation they promote their products in the internet mostly in Instagram; it is like they have extention of their business by being visible online. They mostly communicate with business partners using social media and consider the latter as their major venue for expansion.

Mr. Joselito Bagui, Plant Manager at Grand Trust Feedmill reiterates that they do upgrading of machineries by making it automated. In that case it would mean less labor force needed. In addition, they do benchmarking online as they eye for potential suppliers for their ingredients like corn, soya, polard, and even their micro ingredients like amino acid.

Mr. Kharis Plata, Assistant Manger at Taurus Arrastre and Stevedoring Services which has been operating since 1988 claims that they usually send bills and quotation to their clients online.

The aforementioned are proofs in the actualization of immaterial labor. Immaterial labor, unlike the knowledge worker, is not completely confined to a specific class formation. (Maurizio Lazzarato, "Immaterial Labor," in Marxism beyond Marxism, ed. Saree Makdisi, Cesare Casarino, and Rebecca E. Karl for the Polygraph collective (London: Routledge, 1996), 133.) Lazzarato insists that this form of labor power is not limited to highly skilled workers but is a form of activity of every productive subject within postindustrial societies.

3) The free labor which sustains the Internet is acknowledged within many different sections of the 
digital literature. In spite of the volatile nature of the Internet economy (which yesterday was about community and portals, today is about P2P and wireless connections, and tomorrow, who knows ... ?). The notion of users' labor maintains an ideological and material centrality which runs consistently throughout the turbulent succession of internet fads. Users keep a site alive through their labor, the cumulative hours of accessing the site (thus generating advertising), writing messages, participating in conversations and sometimes making the jump to collaborators.

In Tiziana Terranova's article Free Labor, the author focuses on the social, political, and cultural roles of free labor in the digital economy [1], [12].

4) Tiziana Terranova writes, "Simultaneously voluntarily given and unwaged, enjoyed and exploited, free labor on the Net includes the activity of building Web sites, modifying software packages, reading and participating in mailing lists, and building virtual spaces on MUDs (multiple user domains) and MOOs (MUD object oriented). Far from being "unreal," empty space, the Internet is animated by cultural and technical labor through and through, a continuous production of value [1], [3].

To Terranova's examples of free labor that animates and produces value for the internet, we can add various forms of audiovisual and textual production, such as opinions, commentary, reviews, discussions, videos, songs, images, and all genres of fan production, that people publish everyday on the web. The foundational premise of the concept of "Web 2.0" is a dramatic rise in "user- generated content." Terranova argues that "the internet is about the extraction of value out of continuous, updateable work, and it is extremely labor intensive. It is not enough to produce good Website, you need to update it continuously to maintain interest in it and fight off obsolescence." And currently, the majority of the Internet's updaters - those who create new content for websites, continually renewing interest in them and keeping them "fresh," thus sustaining or even increasing their value over time - are unpaid [1], [3]

Fans' ongoing discussions and expansions of the "universe" of a particular media production serve to advertise the production in these interim, or hiatus, periods. If fans of the original 1960s Star Trek had not continuously, publicly performed their investment in the Trek universe during the $1970 \mathrm{~s}$ - by organizing Trek conventions, publishing Trek fan zines, making and trading Trek uniforms and memorabilia, and so on - it seems doubtful that Paramount would have thought to revive Trek at the end of that decade [3]. Trek fan productions were crucial to maintaining interest in a media text that was, for all intents and purposes, dead since the television series' cancellation in 1969, and when the marketplace favored reinvestment in sci-fi franchises (following the blockbuster box- office performance of 1977's star Wars), the fact that Trek was so alive and well- known to so many, surely informed Paramount's decision to restart the universe with star Trek: The Motion Picture in 1979 (a franchise which Paramount has expanded nearly continuously, with new star Trek television shows and feature films, from 1979 to the present) [3].
Terranova claims, "The digital economy is an important area of experimentation with value and free cultural/affective labor. It is about specific forms of production (Web design, multimedia production, digital services, and so on), but it is also about forms of labor we do not immediately recognize as such: chat, real- life stories, mailing lists, amateur newsletters, and so on. These types of cultural and technical labor are not produced by capitalism in any direct, cause- and- effect fashion; that is, they have not developed simply as an answer to the economic needs of capital. However, they have developed in relation to the expansion of the cultural industries and are part of a process of economic experimentation with the creation of monetary value out of knowledge, culture/affect [1], [3].

As for evidence of the trends described in Free, certain prominent examples are now even more relevant [5]. Chris Anderson in his Free: The Future of a Radical Price notes that YouTube has yet to make money, and it's one of the examples Malcolm Gladwell in his Priced to Sell: Is Free the Future? Cites for why Anderson is wrong. However, the New York Times reported in September 2010 that YouTube was expected to make a profit for the year, with $\$ 450$ million in revenue (which had more than doubled each year for the preceding three years). In March 2011, Citi analyst Mark Mahaney predict revenues of $\$ 1.33$ billion for 2011 and $\$ 1.7$ billion for 2012 (he estimated $\$ 825$ for 2010). In June 2012, he updated his estimates for 2012 to $\$ 3.6$ billion ( $\$ 2.4$ billion after paying partners). And it's working well for users, who can make money from YouTube's Partner Program (the internet created new opportunities for free labor, but many individuals are also harnessing it to make money from their efforts) [13].

Facebook, another internet company Anderson cites as having yet to find a profitable business model, had revenues of $\$ 3.71$ billion in 2011 , with $\$ 1$ billion in profit (83\% from advertising and the rest from Facebook's virtual currency, used for virtual goods in games) [5], [13]].

Free labor is the engine that drives the digital economy, providing a balance between creative production and monetarily useful knowledge work [10]. The demise of factory labor led to the new workers who "have been repeatedly addressed as active consumers of meaningful commodities." Free labor is the result of these consumers' consumption of culture, and their efforts are both "embraced ... and exploited" by the market. The digital economy channels our knowledge exploration in the form of experimental production (web development, software development) as well as untraditional labor (participation in chats, newsletters, social networks, etc.), and commodifies it. However, capitalism isn't "incorporating" the digital culture: it is the origin of it [10].

The digital economy relies on open source free labor to exist. Everything from Apache web server software to forum systems is dominated by open source software. This reliance is one of the ways that late capitalism extracts value from free labor, by both sustaining and exhausting it. In other words, the Internet is both a gift economy and a capitalist economy. It is not a break from capitalism, but a "mutation" of it [10]. 


\section{CONCLUSIONS}

Based on the findings presented, the researcher comes up with the following conclusions.

- Digital economy is not just a phenomenon; it is a formation which intersects on the one hand with the postmodern cultural economy and on the other hand with the information industry that constitutes a challenge to a theoretical and practical engagement with the question of labor.

- Digitization affects the metabolism of the economy the same way it significantly affects the capacity of humans to communicate across time and space. It brings changes to every aspect of commerce, management, and learning throughout the economy.

- Free or immaterial labor is that which produces and supports our networked digital existence. The digital economy is the intersection of culture and economy with the information industry, and is largely embodied in the Internet. Knowledge workers and network technologies converge in this mixed economy supported by the market, the public and free labor.

- The digital economy relies on free labor to exist. Digital economy is an important area of experimentation with value and free cultural/affective labor. It is about specific forms of production but it is also about forms of labor we do not immediately recognize.

\section{REFERENCES}

[1] T. Terranova, "Free labor producing culture for the digital economy," Social Text Summer, vol. 18, Issue 2-63, pp. 33-26p, 2000 .

[2] R. Barbrook, "The high-tech gift economy," in Josephine Bosma et al. Readme, Filtered by Nettime: ASCII Culture and the Revenge of Knowledge, New York: Autonomedia, 1999, pp. 132-138.
[3] A. De Kosnik. Interrogating free 'fan' labor. [Online]. Available: http://spreadablemedia.org/essays/kosnik/\#.UpnaqdLt-uI

[4] A. Feenberg. Review of Moishe Postone, Time, Labor, and Social Domination: A Reinterpretation of Marx's Critical Theory. [Online]. Available:

http://www.sfu.ca/ andrewf/books/Review_Moishe_Postone_Time_ Labor_Social_Domination.pdf

[5] C. Anderson, Free: The Future of a Radical Price, London: Random House Business, 2009.

[6] P. Scannel, Media and Communication, Los Angeles, CA: SAGE Publications, 2009.

[7] C. Doctorow, Chris Anderson's Free Adds Much to the Long Tail, but Falls Short, Guardian News and Media Limited, 2009.

[8] J. Lyotard, "The postmodern condition: a report on knowledge," trans. Geoff Bennington and Brian Massumi, Minneapolis: University of Minnesota Press, 1989.

[9] A. Kroker and M. Weinstein, Data Trash: The Theory of the Virtual Class, New York: St. Martin's, 1994.

[10] Free labor and the digital economy. [Online]. Available: http://mdia590.wordpress.com/2011/02/07/free-labor-and-thedigital-economy/

[11] Thriving in a new economy. [Online]. Available: http://www.businessweek.com/chapter/tapch02.htm

[12] Free labor and the digital economy. [Online]. Available: http://mdia590.wordpress.com/2011/02/07/free-labor-and-thedigital-economy/

[13] M. Gladwell, "Priced to sell - Is free the future?" The New Yorker, Conde Nast Digital, 2009.

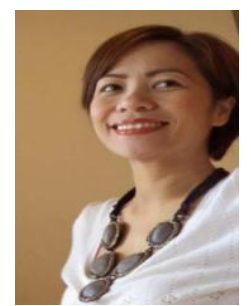

Analiza D. Resurreccion was born in Batangas City, Philippines on March 27, 1977. She is a doctor of philosophy in sociology student at De La Salle University Manila where she completed her master degree of arts in teaching English language. She earned her degree in mass communication at the Lyceum of the Philippines University, Batangas. She started teaching in De La Salle Lipa in 1999. She teaches communication and society, boadcast media, broadcast advertising, and television production. Her first peer-reviewed paper entitled "Media Communications and Sustainable Tourism" was published in IAMURE International Journal of Social Sciences Vol. 3, September 2012. Ms. Resurreccion is an active member of the Philippine Association of Communication Educators Foundation, Inc. 